African Journal of Applied Statistics, home page: www.jafristatap.net

Vol. 1, 2014, pages 13-21.

DOI: http://dx.doi.org/1016929.ajas.2014.1.13.54

\title{
HEDGING FOREIGN EXCHANGE RISKS WITH GOLD: EGARCH APPROACH
}

\author{
S.M. Nuugulu and F. Gideon ${ }^{1}$ \\ University of Namibia
}

\begin{abstract}
This work presents an investigation on whether investments in Gold can serve as a hedge against the depreciation in currencies. The long term relationship between Gold price and the Japanese Yen per US Dollar, British Pound per US Dollar and South African Rand per US Dollar exchange rate was investigated using monthly data on Gold price and the three Dollar exchange rates. Results from the $\mathrm{AR}(2)$ and the $\operatorname{EGARCH}(1,2)$ models suggests that there is a typical inverse relationship between Gold price and the three exchange rates. This relationship differed among the three currencies. The strongest relationship was observed in the British Pound exchange rate, making the Pound the strongest hedge among the three considered currencies.
\end{abstract}

Keywords: Hedging, Foreign Exchange Risk, Gold, EGARCH, Volatility modelling.

AMS 2010 Subject Classification: 91B24, 91G70.

2000 JEL Classification: G13.

Copyright (C) 2014, African Journal of Applied Statistics. All rights reserved

Article history: Received 2014/01/01; Accepted 2014/10/30; Published Online 2014/11/30.

\section{INTRODUCTION}

The 2007-2008 World economic crisis scared investors and the need for a secure hedge against the downward surges in the USD (being the common international trading currency) has become very imperative. Gold being a precious mineral for many millenniums has thus come to the core of investigation. According to [Webography Gold market (2011)] Gold has always been a good currency hedge and Capie et al. (2005) quoted the following statement made by Charles de Gaulle,

There can be no other standard than Gold.

Yes, Gold which never changes, which can be shaped into ingots, bars, coins, which has no nationality and which is externally and universally accepted as the unalterable fiduciary value par excellence"

These summarise the long held view of Gold as a store of value, and many refereed to it as durable and divisible and for many years it has been an ultimate standard of value, and not only that, but a standard which held a steady purchasing power in terms of goods over a very long period of time.

An asset can be a hedge against a currency in two ways; that is, against the internal and external purchasing power of that currency. Gold can thus be a hedge against the internal purchasing power of a currency when its appreciation in value offsets the loses due to the inflation of that particular country. Hedging against the external purchasing power of a currency refers to when it can be used to protect against the depreciations in the foreign exchange rates of that particular country. For example when the USD weakens, relative to the South African Rand, one USD can only buy a few goods in South Africa as compared to when the currency was strong. This can pose a greater risk to investors in offshore investments. Hence the relevance of investigating whether Gold could possible be used as a protection against such risks. For Gold to be a perfect hedge against the inflation, Gold price should move in the same direction and at the same rate and time with the consumer price index (CPI) of that particular country. On the other hand for Gold to be a perfect hedge against the foreign exchange rates, the price of Gold and the foreign exchange rate should move in the opposite direction, at the same rate and time. If such a relationship exists between the price of Gold and the exchange rates, one can use the two assets as hedging instruments, since the gains in one offsets the loss in the other, i.e when the currency depreciates one can shift their investments in currency shares to investments in Gold and vice versa.

Figure 1 below shows how the 2007-2008 crisis affected the value of the USD.

${ }^{1}$ Corresponding author: (S.M. Nuugulu): profnuugulu@yahoo.co.uk S.M. Nuugulu, snuugulu@unam.na, profnuugulu@yahoo.co.uk. University of Namibia, Windhoek, Namibia. Tel numbers: +264-612063962, fax: +264-61-2063791

Co-author: F Gideon. fgideon@unam.na. University of Namibia, Private Bag 13301, Windhoek, Namibia, telephone: , telephone: +26461-2063793, fax: +264-61-2063791 


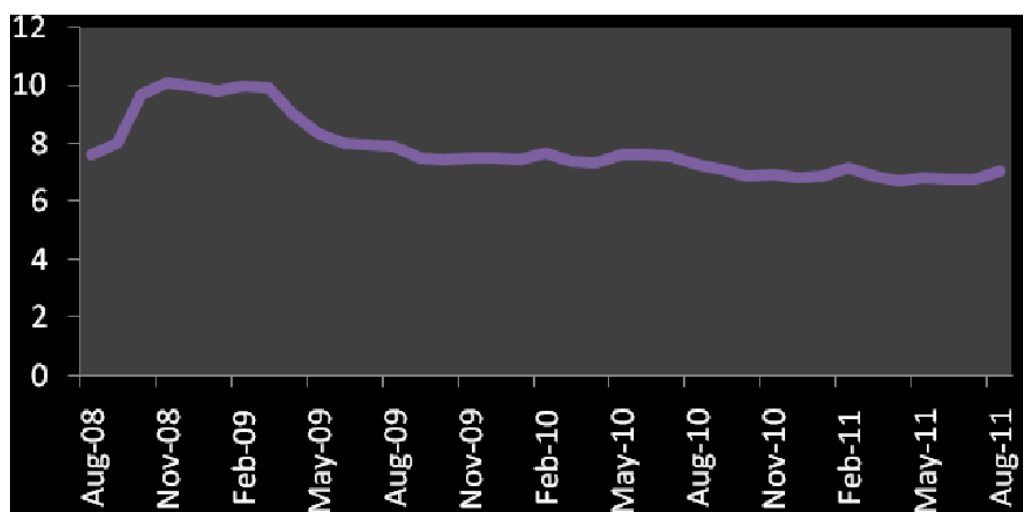

Figure 1.1. The Down ward surge in the Dollar

After the 2007-2008 economic crisis, there was a steady decline in the value of the USD. The decline consequently lowered investor's confidence in any currency dominated stocks and bonds, as the security of investing in them has been compromised. In the presence of such uncertainties, alternative safe investment options should be explored. Webography Gold market (2011) emphasized that, Investors have long regarded Gold as a good protection against depreciation in currency values. The defensive properties of Gold apply both internally (i.e. against inflation) and externally (against exchange rates).

\section{Average monthly gold prices since 1971}

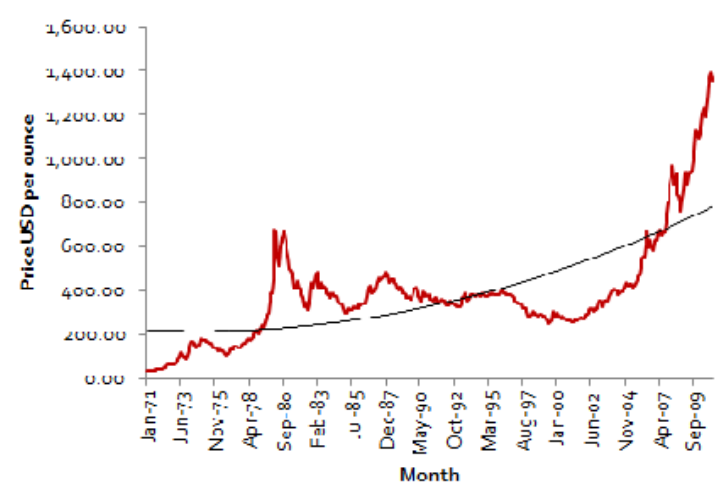

The relationship between the price of Gold and the exchange rates important for national economic decisions since most central banks maintain a proportion of their foreign exchange reserves. Thus, knowledge on how a good currency hedge Gold is, can help Central Banks in setting up their foreign reserves. Figure 2 below shows the plot of the change in Gold price coupled with the change in the USD by Rand exchange rate from 1971 to 2011. The graphs indicates that there is a typical inverse relationship between price of Gold and the Dollar by Rand exchange rate. Hence, the relationship between Gold and the South African currency has come to the fore of investigations.

Figure 1.2. Average Monthly Gold Prices versus USD per Rand exchange rate

The price of Gold has been increasing very sharply over the past years, reaching a highest record of approximately $1,356.40$ USD in January 2011 as observed in Figure 3 below. These rises in Gold price has consequently pushed up its demand.
In contrasting Figure 1 and 3, one can reasonably hypothesise a typical inverse relationship between Gold Price and the exchange rates. 


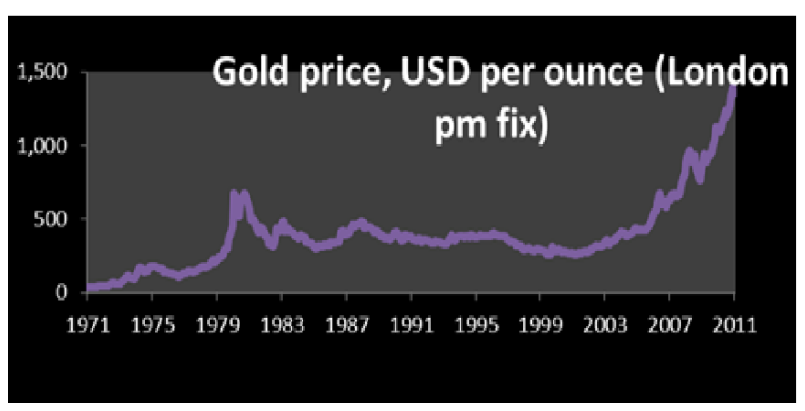

Figure 1.3. Gold Price based on the London PM fix

The objective of this paper is of three folds, firstly it serve to asses empirically as to how a good currency hedge has Gold been for the past 39 years (1971 to 2010) - evidence from the EGARCH model. Secondly, to explain how persistent is volatility in Gold Price subject to fluctuations in currencies. And thirdly to asses the effects of good news and bad news on volatility in Gold Price. The analyses of the paper is based on three main foreign Dollar currencies. These currencies have been in existence throughout the entire sampling period. The considered currencies are; the British Pound, the Japanese Yen, and the South African Rand. The EGARCH model has been used previously by researchers such as Capie et al. (2005). The used quarterly data on Gold Price, Pound and Yen by Dollar exchange rates. This paper present an extension the work by Capie et al. (2005) by using more frequent monthly data and adding an additional Rand by Dollar exchange rate to the Pound and Yen, which helps in assessing the relationship between Gold and the South African Rand. Our data on Gold price (in USD per ounce) based on the London 3:00 PM Fix was obtained from Webography Gold market (2011), while those on the three exchange rates were obtained from Financial Forecast Centre, Board of Governors of the Federal Reserve System (USA) (2011). The results indicates that; indeed Gold has been a currency hedge, but it has only done so to a degree that seem highly dependent on somewhat unpredictable exchange regimes.

1.1. Main Questions and Article Outline. In this subsection we discuss the main research questions the paper is trying to address as well as setting out the overall structural organization of the paper.

(1) To what extent can Gold serve as a currency hedge?

(2) How does Gold hedging ability differs among the considered currencies?

(3) How does Gold hedging ability differs among the considered currencies?

The article is organized as follows. Section 1 highlights the background and history of Gold as a hedge while addressing the context and importance of the research. The section further outlines the objectives of the study, research questions and provide the overall outline of the paper. Section 2 summarise previous literatures on the subject "Gold as a hedge". Section 3 present the data issues and model specifications. While section 4 presents the results and discussions. Section 5 presents conclusions and future directions, the paper then ends with a list of references.

\section{Literature}

This section presents a brief summary of previous literatures on the subject "Gold as a hedge."

2.1. Gold as an inflationary hedge. After the breakdown of the Breton Woods system in 1971, investors started to look for currencies that are safe havens. These currencies were however prone to economic and political risks. It was at that time that investing in Gold turned out to be a way of hedging the risks, see for instance Jastram (2009). Some researcher on the subject such as Lawrence (2003) believe that Gold is different from other physical assets since its potentials and response to price are highly liquid. It is because of this views that the notion of Gold as a hedge came on the spotlight. Webography Gold market (2011) Investigated the inflationary hedging ability of Gold and concluded that Gold is an effective hedge against inflation, which is hypothetically inversely correlated to the USD and thus a good currency hedge. ? further extended on the results by Webography Gold market (2011) by arguing that if Gold can be a hedge against inflation, then changes in the returns on Gold investments should systematically offsets changes in the general price level of that particular country.

The subject on "Gold as an inflational hedge" has been extensively studied. Worthington and Pahlavani (2006) investigated the subject using a structural cointegration approach , they also argues that, the approach allows for structural breaks. Their results supports the widely held view that, direct and indirect investments in Gold can protect risks due to inflation. Worthington and Pahlavani (2006). However emphasised that, the quality of the inflation hedging ability of Gold depends on the presence of a stable-long run relationship between the price of Gold and the inflation rate. ? did a comparative study to investigate which one between Oil and Gold is a better inflationary hedge in Turkey, their results indicate that, the consumer price index (CPI) is highly correlated to Gold price than is to Oil price.

2.2. Gold as a currency hedge. In literature, different approaches has been used in modelling the currency hedging ability of Gold. These approaches can be broadly divided into two main groups, linear and non-linear approaches. 
2.2.1. Linear Approach. The investigation "Gold as a hedge against the Turkish Lira" by Ozturk and Acikalin (2008) applied the following linear model to investigate the hedging ability of Gold on the Turkish Lira;

$$
\begin{array}{r}
G P_{t}=c_{0}+\sum_{i=1}^{m} c_{i} G P_{t-i}+\sum_{j=1}^{m} d_{j}(T L / \$)_{t-j}, \\
(T L / \$)_{t}=d_{0}+\sum_{j=1}^{m} d_{j}(T L / \$)_{t-j}+\sum_{i=1}^{m} c_{i} G P_{t-i}+w_{t},
\end{array}
$$

where $G P_{t},(T L / U S \$)_{t}$ and $w_{t}$ represents the price of Gold, the Turkish lira per USD exchange rate and the error term respectively. Their results indicates that, Gold is indeed an effective hedge against potential Turkish Lira depreciations.

Another study by Capie et al. (2005) also approached the subject from a log linear perspective. They investigated the currency hedging ability of Gold on the British pound and the Japanese Yen. Their log linear model is of the form;

$$
\Delta G_{t}=\alpha_{0}+\alpha_{1} \Delta G_{t-1}+\beta_{0} \Delta X_{t}+\beta_{1} \Delta X_{t-1}+\epsilon_{t},
$$

where $\Delta G_{t}, \Delta X_{t}$ and $\epsilon_{t}$ represents, change in Gold price, change in the exchange rate and the error term, respectively.

2.3. Non-linear Approach. Using the non-linear approach Kuan-Min and Yuan-Ming (2010) investigated whether Gold could serve as an exchange rate hedge in Japan. They argue that their study is unique in the sense that it was the first of its kind to use a non-linear model to investigate the relationship. Kuan-Min and Yuan-Ming (2010) used a non-linear Threshold Vector Autoregressive (TVAR) Model, which they argue better explain the hedging relationship by taking into consideration the structural changes due to extreme fluctuations.

The Threshold Vector Autoregressive (TVAR) Model used by Kuan-Min and Yuan-Ming (2010) uses an optimal threshold value to divide the dynamics of the exchange rate fluctuations:

$$
\begin{gathered}
\Delta G_{t}=\alpha_{1,0}+\sum_{i=1}^{p} \alpha_{11 i} \Delta G_{t-i}+\sum_{i=1}^{p} \alpha_{1,2 i} \Delta e_{t-i}+\epsilon_{g 1 t} \\
\Delta e_{t-d}>\gamma, \\
\Delta G_{t}=\alpha_{2,0}+\sum_{i=1}^{p} \alpha_{21 i} \Delta G_{t-i}+\sum_{i=1}^{p} \alpha_{2,2 i} \Delta e_{t-i}+\epsilon_{g 2 t} \\
\Delta e_{t-d} \leq \gamma, \\
\Delta e_{t}=\beta_{1,0}+\sum_{i=1}^{p} \beta_{1,1 i} \Delta e_{t-i}+\sum_{i=1}^{p} \beta_{1,2 i} \Delta e_{t-i}+\epsilon_{g 1 t} \\
\Delta e_{t-d}>\gamma, \\
\Delta e_{t}=\beta_{2,0}+\sum_{i=1}^{p} \beta_{2,1 i} \Delta e_{t-i}+\sum_{i=1}^{p} \beta_{2,2 i} \Delta e_{t-i}+\epsilon_{g 1 t} \\
\Delta e_{t-d} \leq \gamma,
\end{gathered}
$$

where $\Delta G_{t}$ and $\Delta e_{t}$ represents the change in Gold price and the change in the exchange rate respectively. According to their results, there is a negative relationship between Gold price and the Yen exchange rate, hence concluding that, Gold can indeed be an effective hedge against volatility in the Yen. This relationship is however said to have shifted between the two regimes of fluctuations in the Yen, regimes of high volatility $\left(\Delta e_{t-d}>\gamma\right)$ and those of low volatility $\left(\Delta e_{t-d} \leq \gamma\right)$.
Though Kuan-Min and Yuan-Ming (2010) criticized the use of linear models, Capie et al. (2005) are in full support of their choice for a linear model. Capie et al. (2005) argues that applying natural logarithm to the data helps in normalizing and regulating the destabilizing extreme fluctuations in the data. Ashley and Patterson (1989) supports the view of Capie et al. (2005) by asserting that; most macroeconomic models are either linear or log linear, supporting the use of linear or log linear models in modelling financial data.

\section{Data And Methods}

In this section we present a brief discussion on the data as well as on the models used in analysing the them.

3.1. The Data. The data used in this study consists of monthly observations on Gold price in USD per ounce, English Pound per USD, Japanese Yen per USD and South African Rand per USD exchange rates. The sample runs from January 1971 through April 2010 with a total of 471 observations. The data was analysed in $E$ - views7 econometric data analysis package.

3.2. Methods. This subsection presents the discussions on the development of the models used in the analysis.

3.2.1. Autoregressive (AR) Model. The study employed the Autoregressive (AR) lag model similar to the one used by Capie et al. (2005). The general model takes the form;

$$
\Delta G_{t}=\alpha_{0}+\alpha_{1} \Delta G_{t-1}+\beta_{0} \Delta X_{t}+\beta_{1} \Delta X_{t-1}+\epsilon_{t}
$$

The model imply that, current change in Gold price $\Delta G_{t}$ is linearly dependent on its change at first lag $\Delta G_{t-1}$, and on current and previous change in the exchange rates generically denoted by $\Delta X_{t}$ and $\Delta X_{t-1}$ respectively with some time dependent error term $\epsilon_{t}$.

This AR model falls under the class of classical Ordinal Least Squares (OLS) models. An OLS model is said to be unbiased and efficient, if and only if ; its prediction errors are homoskedastic and serially uncorrelated. The efficiency of an OLS model is lost if its error terms heteroskedastic(unequal variance), i.e, the model predictions exhibits some periods of unusual large volatilities, followed by some periods of relative calms, i.e;

$$
\epsilon_{t}=\sigma_{t} Z_{t}
$$

That is; the error term $\epsilon_{t}$ is a function of a time dependent standard deviation $\sigma_{t}$ and some stochastic variable $Z_{t}$. To improve on the model predictions analysts often fit additional volatility modelling parameters to better explain the volatility$\left(\sigma_{t}^{2}\right)$. 
3.3. Volatility modelling. If the error terms equation(3.5) are heteroskedastic, then the forecasts and variances predictions of equation(3.5) may be misleading. A conversional remedial measure is to re-estimate the model and fit GARCH parameters. Instead of using some ad hoc variable choices, Engel (1982) proved that it is possible to simultaneously model the mean and the variance of an asset returns by developing a methods that model the mean return of an asset and its volatility. Enders (2010) explains Engel (1982) volatility modelling methodology as follow;

Suppose one estimate the stationary OLS model

$$
y_{t}=\alpha_{0}+\alpha_{1} y_{t-1}+\epsilon_{t},
$$

and want to forecast $y_{t+1}$. The conditional mean of the forecast $y_{t+1}$ is given by

$$
E_{t}\left(y_{t+1}\right)=\alpha_{0}+\alpha_{1} y_{t} .
$$

If we use these conditional mean to forecast $y_{t+1}$, the forecast error variance is $\sigma^{2}$. However if the unconditional forecasts are used, the mean of the unconditional forecast is always the long-run mean of the $y_{t}$, that is, equal to $\alpha_{0} / 1-\alpha_{1}$. The unconditional error variance is therefore given by

$$
\sigma^{2} / 1-\alpha_{1}^{2} \text {. }
$$

Since the unconditional forecast $1 / 1-\alpha_{1}^{2}>1$ has greater variance as compared to the conditional forecasts. The conditional forecasts are therefore preferred over the unconditional ones.

3.3.1. Autoregressive Conditional Heteroskedasticity (ARCH) Modelling. The conditional forecast of the variance in a model of the form

$$
y_{t}=\alpha_{0}+\alpha_{1} y_{t-1}+\epsilon_{t},
$$

where the variance of the error term $\epsilon_{t}$ is not a constant can be modelled as an Autoregressive Conditional Heteroskedasticity $\mathrm{ARCH}(\mathrm{q})$ process by taking the squares of the estimated error terms

$$
\hat{\epsilon}_{t}^{2}=\alpha_{0}+\alpha_{1} \hat{\epsilon}_{t-1}^{2}+\alpha_{2} \hat{\epsilon}_{t-2}^{2}+\ldots+\alpha_{q} \hat{\epsilon}_{t-q}^{2}+\tau_{t},
$$

where $\tau_{t}$ is a white-noise process. If $\alpha_{1}=\alpha_{2}=\ldots=\alpha_{q}=0$, then $\hat{\epsilon}_{t}^{2}=\alpha_{0}$ then we have a situation of a constant variance (homoskedasticity).

3.3.2. Generalized Autoregressive Conditional Heteroskedasticity (GARCH)modelling. Bollerslev (1986) extended Engel (1982) original work by developing a technique that allows the conditional variance to be modelled as an ARMA process. Enders (2010) explains the extension of Engel (1982) work by

4.2. Stationarity test. The Augmented Dickey-Fuller (ADF) test was used to verify the possible presence of unit root in the four log data series. Table 1: below shows that all the series are non stationary at level. However, they all became

4.2.1. Pairwise Cross Correlation. Table 2: below shows the pairwise cross correlations between Gold price and the three exchange rates. All the correlations between Gold price and
Bollerslev (1986) as follows;

Let the heteroskedastic error process be that, $\epsilon_{t}=\tau_{t}\left(h_{t}\right)^{1 / 2}$ where $\sigma_{\tau}^{2}=1$ and

$$
h_{t}=\alpha_{0}+\sum_{i=1}^{q} \alpha_{i} \epsilon_{t-i}^{2}+\sum_{i=1}^{p} \beta_{i} h_{t-i} .
$$

Since $\tau_{t}$ is a white-noise process, the conditional and unconditional means of the error term $\epsilon_{t}$ are all equal to zero. Therefore by finding the expected value of $\epsilon_{t}$ is easy to verify that:

$$
E\left(\epsilon_{t}\right)=E\left(\tau_{t}\left(h_{t}\right)^{1 / 2}\right)=0 .
$$

3.3.3. The EGARCH model in modelling financial data. A special case of GARCH model known as the EGARCH model, is specially designed to allows for asymmetric effects of good news and bad news. The EGARCH model was first proposed by Nelson (1991). This model is more appropriate in modelling financial data as it does not require non negativity constraints, as is the case with standard GARCH models. The general EGARCH model takes the following format;

$\log h_{t}=\alpha_{0}+\sum_{i=1}^{q} \alpha_{i} \frac{\epsilon_{t-1}}{h_{t-1}^{\frac{1}{2}}}+\sum_{i=1}^{q} \lambda_{1}\left|\left(\frac{\epsilon_{t-1}}{h_{t-1}^{\frac{1}{2}}}\right)\right|+\sum_{i=1}^{p} \beta_{1} \log h_{t-1}$

where by $h_{t}$ is the conditional error variance. This EGARCH model has three interesting features. The model is in log-liner form, hence regardless of the magnitude of $\log \left(h_{t}\right)$, the implied value of $h_{t}$ can never be negative. Hence, it is permissible for the coefficients to be negative. Instead of using the value of $\epsilon_{t-1}^{2}$ the EGARCH model uses the level of standardized value of $\epsilon_{t-1}$, that is $\epsilon_{t-1} / h_{t-1}^{1 / 2}$, this standardized value allows for more natural interpretations of the size and the persistence of the shocks in the price of the asset. The EGARCH model is also permissible for leverage effects. That is; if $\epsilon_{t-1} / h_{t-1}^{1 / 2}$ is positive, then the effect of the shocks on the log of the conditional variance is $\alpha_{1}+\lambda_{1}$. If $\epsilon_{t-1} / h_{t-1}^{1 / 2}$ is negative, the effect of the shock on the conditional variance is $-\alpha_{1}+\lambda_{1}$.

\section{Results And Discussions}

In this section we discuss the results of the study in relation to the adopted methodologies, starting with the distribution of the logged data series up to the fitted EGARCH model.

4.1. Distribution of the log data. After applying natural logarithm on the original data series, we obtained better symmetrical distributions on all the four series, rendering the classical AR model fit to model the data. The symmetric distribution of the four series can be seen in Figure 4: below.

stationary at 1st difference, hence they are all I(1)- integrated of first order.

the three exchange rates are negative, indicating that Gold can indeed be used as a currency hedge. 

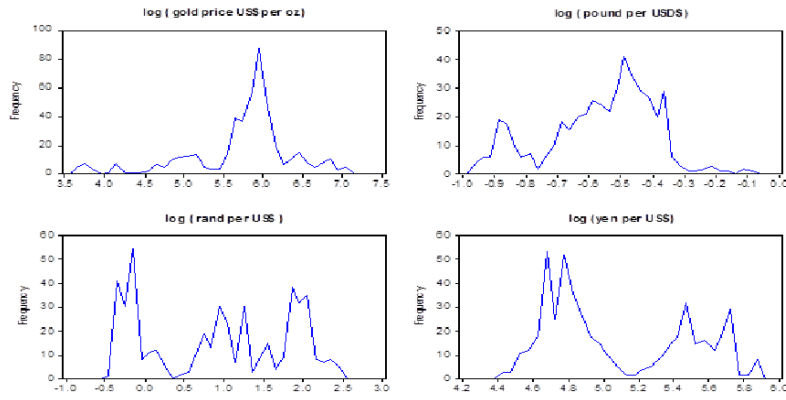

FiguRE 4.4. Symmetric distributions of the four log data series

\begin{tabular}{l|c|c|c|c|c}
\hline \hline \multicolumn{6}{c}{ Augumented Dickey-Fuller (ADF) test } \\
\hline \hline Significance level & Statisitcs & Log Gold Price & Log Pound per $\$$ & Log Rand per $\$$ & Log Yen per $\$$ \\
\hline & p-value & 0.0785 & 0.0901 & 0.08071 & 0.4830 \\
& critical value & $\mathbf{- 2 . 6 7 8 7 6 3}$ & $\mathbf{- 2 . 6 1 7 2 1 9}$ & $\mathbf{- 0 . 8 3 7 1 4 6}$ & $\mathbf{- 1 . 5 9 7 6 8 8}$ \\
1\% Level & t-value & -3.444068 & -3.444039 & -3.444039 & -3.444039 \\
$5 \%$ Level & t-value & -2.867483 & -2.867470 & -2.867470 & -2.857470 \\
$10 \%$ Level & t-value & -2.569998 & -2.569991 & -2.569991 & -2.569991 \\
\hline \hline
\end{tabular}

Figure 4.5. Table 1: Stationarity test

\begin{tabular}{|c|c|c|c|c|}
\hline \multicolumn{5}{|c|}{ Pairwise cross correlation between the four data series } \\
\hline Data Series in first differences & $\overline{\Delta G_{t}}$ & $\Delta R_{t}$ & 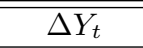 & $\Delta P_{t}$ \\
\hline$\overline{\Delta G_{t}}$ & 1.000000 & & & \\
\hline$\Delta R_{t}$ & -0.232705 & 1.000000 & & \\
\hline$\Delta Y_{t}$ & -0.247733 & 0.222084 & 1.000000 & \\
\hline$\Delta P_{t}$ & -0.282352 & 0.377391 & 0.346542 & 1.000000 \\
\hline
\end{tabular}

Figure 4.6. Table 2:Pairwise Cross Correlation

4.3. Classical AR model results. The fitted AR model is of the form;

$$
\Delta G_{t}=\alpha_{0}+\alpha_{1} \Delta G_{t-1}+\beta_{0} \Delta X_{t}+\beta_{1} \Delta X_{t-1}+\epsilon_{t} .
$$

On fitting this model, parameter estimates for $\alpha_{0}$ and $\beta_{1}$ for all the three exchange rates were not statistically significant at $1 \%$ level of significance. To reduce redundancy and improve the fitness of the model, the insignificant parameters were dropped to obtain a better improved model. The generic improved model takes the form.

$$
\Delta G_{t}=\alpha_{1} \Delta G_{t-1}+\beta_{0} \Delta X_{t}+\epsilon_{t} .
$$

This model is estimated on the three exchange rates to obtain the following mean equations;

\section{Pound Mean Equation}

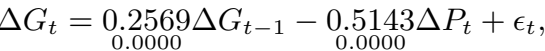

$$
\begin{aligned}
& \Delta G_{t}=\underset{0.0000}{0.2740 \Delta} G_{t-1}-\underset{0.0000}{0.4361 \Delta Y_{t}}+\epsilon_{t},
\end{aligned}
$$

\section{Rand Mean Equation}

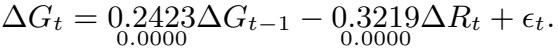

The estimates for $\beta_{0}$ in the three models under equation (4.13) are all negative, indicating an inverse relationship between Gold and the three exchange rates. These observations supports our hypothesized object that "Gold can be used as a currency hedge". However, the study of the extent to which Gold has served as a currency hedge in the three considered foreign dollar currencies forms the subject of the remainder of this section.

4.4. Shortcomings in the Classical AR model. Figure 5: below shows the residual plot from the Pound exchange rate mean equation estimated in equation (4.13). Similar plots were obtained from the Yen and Rand mean equations.

All three residual plots depicts regimes of high volatility and those of low volatility, hence violating the homoskedastic assumption of the classical AR model. To support these graphical evidence, results from the Breusch-Pagan-Godfrey test for heteroskedasticity indicates that there is a presence of heteroskedastic disturbances in all three models estimated in equation (4.13). Therefore to help explain the differential effects of these disturbances on the volatility in Gold price we fitted GARCH parameters to the models in equation (4.13).

4.5. On fitting the GARCH parameters. The conditional error variance $\sigma_{t}^{2}$ in the three equations was modelled as $\mathrm{ARCH}$ 
process which takes the form;

$$
\sigma_{t}^{2}=\alpha+\beta_{1} \sigma_{t-1}^{2}+\beta_{2} \sigma_{t-2}^{2}+\ldots+\beta_{n} \sigma_{t-n}^{2}+\tau,
$$

for some constant variance $\tau$.

A variety of $\mathrm{ARCH}$ processes with different lag values were fitted: the conventional GARCH process, the Threshold ARCH process (TARCH), and the exponential GARCH process $(\mathrm{EGARCH})$ with error terms $\epsilon_{t}$ either normally distributed, students $t$ distributed or generalised exponentially distributed. The combination of the process and innovation distribution that produced the minimum AIC, RSS and SBC values was selected. EGARCH $(1,2)$ process with error terms Normal distributed was selected for all three exchange rates.
The selected $\operatorname{EGARCH}(1,2)$ model takes the form;

$$
\begin{gathered}
\log \sigma_{t}^{2}=\alpha+\beta \log \sigma_{t-1}^{2}+\omega \log \sigma_{t-2}^{2}+\gamma\left|\frac{\epsilon_{t-1}}{\sigma_{t-1}}\right|+\phi \frac{\epsilon_{t-1}}{\sigma_{t-1}},(4 \\
\epsilon_{t} N\left(\mu, \sigma_{t}^{2}\right)
\end{gathered}
$$

where $\sigma_{t}^{2}$ is the volatility and $\tau, \beta, \omega, \gamma$, and $\phi$ are the parameters to be estimated. The parameter, $\phi$ represents the symmetric effects of the model, while the GARCH effect parameters $\sigma$ and $\omega$ measure the persistence of volatility in Gold Price irrespective of what is happening in the Gold market. The parameter $\gamma$ measures the leverage effects of the model. If $\gamma<0$, then sudden increase in Gold price (good news) generates less volatility as compared to sudden decrease in Gold price (bad news). If $\gamma>0$, then increase in Gold generate more volatility as compare to the decrease. The reduced models with the fitted GARCH parameters are as follow:

\section{Pound:}

$$
\begin{aligned}
& \Delta G_{t}=\underset{0.0002}{0.182 \Delta G_{t-1}}-\underset{0.0000}{0.378 \Delta} \Delta P_{t}+\epsilon_{t}, \\
& \log \sigma_{t}^{2}=\underset{0.0000}{0.814}+\underset{0.0135}{0.530} \log \sigma_{t-1}^{2}+\underset{0.0709}{0.383} \log \sigma_{t-2}^{2}+\underset{0.0000}{0.326}\left|\frac{\epsilon_{t-1}}{\sigma_{t-1}}\right|+\underset{0.0004}{0.145} \frac{\epsilon_{t-1}}{\sigma_{t-1}} . \\
& \text { Yen: }
\end{aligned}
$$

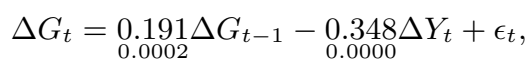

$$
\begin{aligned}
& \log \sigma_{t}^{2}=\underset{0.0000}{-0.756}+\underset{0.0233}{0.593} \log \sigma_{t-1}^{2}+\underset{0.1905}{0.329} \log \sigma_{t-2}^{2}+\underset{0.0000}{0.343}\left|\frac{\epsilon_{t-1}}{\sigma_{t-1}}\right|+\underset{0.0068}{0.094} \frac{\epsilon_{t-1}}{\sigma_{t-1}} .
\end{aligned}
$$

Rand:

$$
\begin{aligned}
& \Delta G_{t}=\underset{0.0000}{0.198 \Delta G_{t-1}}-\underset{0.0000}{0.252 \Delta R_{t}+\epsilon_{t}}, \\
& \log \sigma_{t}^{2}=\underset{0.0000}{0.795}+\underset{0.0097}{0.599} \log \sigma_{t-1}^{2}+\underset{0.1617}{0.318} \log \sigma_{t-2}^{2}+\underset{0.0000}{0.349}\left|\frac{\epsilon_{t-1}}{\sigma_{t-1}}\right|+\underset{0.0010}{0.130} \frac{\epsilon_{t-1}}{\sigma_{t-1}} .
\end{aligned}
$$

The estimates for $\beta_{0}$ in all three equations are negative, confirming that Gold can indeed be used as a hedge against the three dollar foreign currencies. Looking at the magnitude of the estimate for $\beta_{0}$ in the Rand equation, it is not surprising that the Rand is the weakest hedge of all the three currencies. Figure 6: below shows the time series plots of Gold Prices and the three currencies.
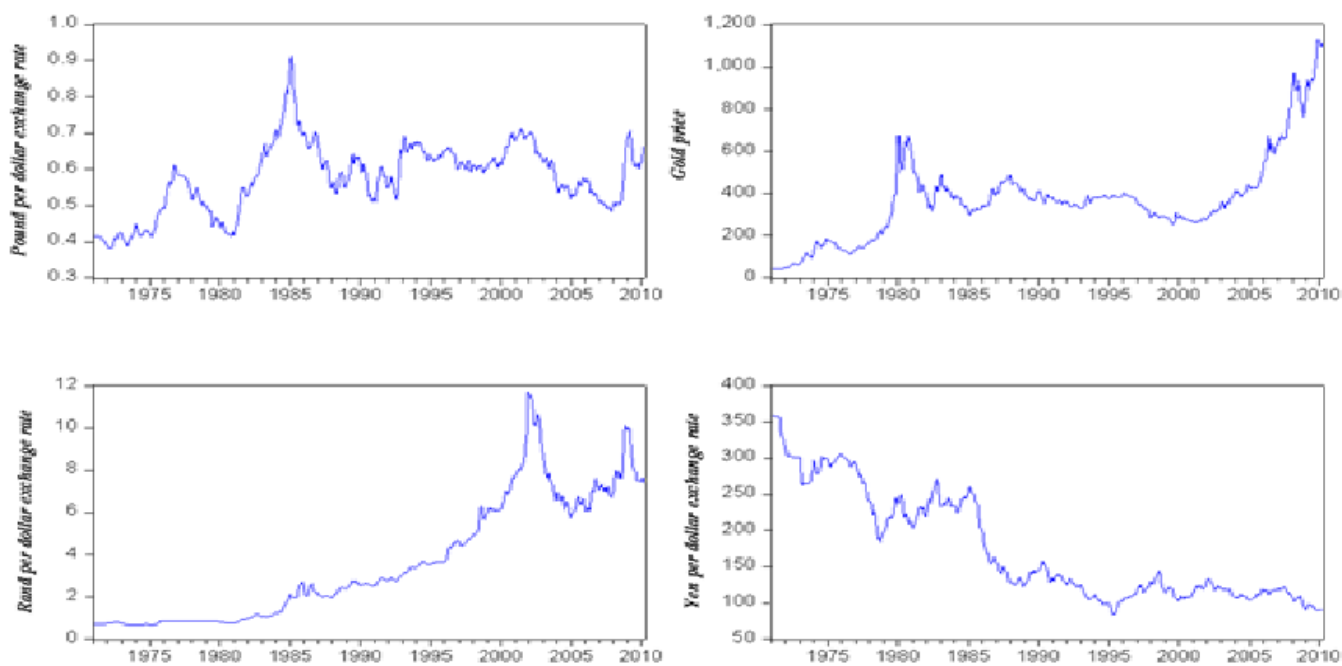

FIgURE 4.8. Pound per USD, Gold Price, Rand per USD and Yen per USD, time series plots 
Based on Figure 6: above, The Pound and Yen graphs moves in the opposite direction with that of Gold Price, hence their relatively stronger negative relationships seen in equation (4.16). Clearly as Gold Price increases, the Pound and the Yen strengthen relatively to the USD.

However, from the Rand exchange rate plot, there has been no consistent negative trend as it shifted now and then. From 1971 to the early 1980s, there seem to be a positive relationship between the Rand and Gold, as the Rand has been weakening with increase in Gold price. However, from the late 1980s to around 2001, when Gold price was decreasing, the Rand weakened relatively, hence depicting an inverse relationship. From late 2001 to around 2008, the Rand strengthened with increase in the Gold price still maintaining a negative relationship. There seem to have been no consistent trend in the relationship between the Rand and Gold price. This translate well to its minimal inverse relationship with Gold depicted in equation (4.16) above.

It is however not surprising that the Rand is the weakest hedge. The weakness in the strength of the inverse relationship between Gold and the Rand can be attributed to a couple of factors. South Africa is one of the top 10 leading world Gold exporters. Increases in Gold Price, would mean optimistic foreign investors and Central Banks are now more willing to invest in the South African Gold as a store of value, these consequently would mean more forex to South African and hence the weakening in the domestic value of its Rand.

Conversely when Gold price decreases, there is likely to be an oversupply of Gold in the market due to ultimate forces of supply and demand. In this case, Investors and Central Banks are now less willing to buy the freshly produced South African Gold, they would be better off by buying Gold reserves from countries like China. In a long-run these strengthen the Rand relatively to the USD.

We can therefore concluded that the negative relationship between the Rand and Gold observed in equation(4.16)is short lived and that in a long run one expect a consistent positive relationship. This then makes the Rand a riskiest hedge of all considered currencies since on the long-run the risk in the Rand shares is expected to be of a relatively same magnitude and effects as that in the Gold shares, hence making the two shares weakest hedge of each another.

These findings are of great importance to governments and investors who would like to hedge foreign exchange risks with investments in Gold and vice versa. For governments or investors who would like to hedge their investments in Gold shares with currencies shares, it is thus recommended that the best and safest options would be to invest in the Pound or Yen shares in contrast to the Rand shares. Hedging with Rand shares is much more risky as compared to hedging with the Pound and Yen shares. Similarly, for investors in Rand shares it is least advisable for them to hedge their investments with Gold shares since the two shares (Gold and Rand) are directly linked and move in the same direction.

From the conditional error variance equations; the statistical significance of both $\frac{\epsilon_{t-1}}{\sigma_{t-1}}$ and its absolute value $\left|\frac{\epsilon_{t-1}}{\sigma_{t-1}}\right|$ implies that, error terms have asymmetric effects on the volatility. Since the estimates for $\phi$ - the symmetric effect parameter and $\gamma$ - the leverage effect parameter are all positive then, $\epsilon_{t-1}>0$, which implies that good news-sudden unanticipated increase in Gold price generates greater volatility as compared to the bad news-sudden decrease in Gold price.

The GARCH effect parameter estimates $\beta$ and $\omega$ all sum up to $0.913,0.922$ and 0.917 with respect to the Pound, Yen and Rand equations respectively. Since all these values are almost closer to 1, then shocks in Gold prices are extremely persistent, that is, volatility in Gold price takes a very long time to die out after a crisis in the Gold market. These can be seen from the estimated conditional standard deviations $\sigma_{t}$ plot for the Pound exchange rate in Figure 7: Similar graphs were obtained with respect to the Yen and Rand exchange rates.

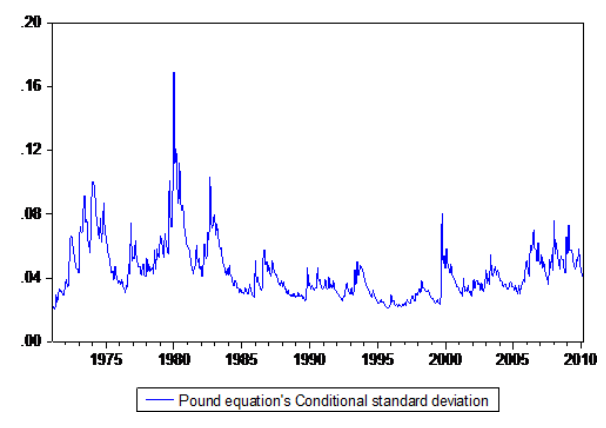

Figure 4.9. Conditional Standard Deviation plot of the Pound equation

From Figure 6 above, large upward runs in Gold price began in the early 1970s and ended sometimes in the early 1980s at a peak of $\$ 835$ an ounce. Likewise from Figure 7 above the volatility was high throughout these period from 1970 until the early 1980s. These was prior to the breakdown of the monetary system called the Gold Standard or Bretton Woods system. Such high fluctuations in Gold price could greatly be traced back to the breakdown of the Bretton Wood system. After that regime shifts in the Gold market, volatility started stabilizing from the mid-1980s onwards. However it started picking up again in 1999 and kept fluctuating till 2003 when it dropped reaching the minimum in 2005. These fluctuations, 
as well as the incredible high rate of price increase, especially from mid-2005 have generated a lot of journalistic interest and are not only important to the world but also important to South Africa, since South Africa has consistently been one of the world top ten leading Gold producers for the last 120 years.

After 2006 volatility has been fluctuating reaching the highest level in 2009. Such behaviours in the price of Gold could be traced back to a probable reaction to the 2007-2008 world economic turmoil. After this, volatility then gradually dropped until the earlier months of 2010.

\section{Conclusions And Future directions}

In conclusion, our results indicate that Gold has indeed served as hedge against fluctuations in the three foreign exchange value of the USD for the period under investigation. However the extent to which Gold served as hedge varies among the three Dollar foreign currencies. However the hedging relationship is found to be short lived since there are no long run relationships between the three exchange rates and the price of Gold.

The British Pound and the Japanese Yen provided the strongest hedging relationships with Gold as compared to that with the South African Rand. The strength of the hedging relationship between Gold and the South African Rand was the weakest, making the Rand the most riskiest Gold hedging instrument as compared to the Yen and Pound. These is primary anticipated to the fact that South Africa is one of the world leading Gold exporters and Gold being its primary export commodity, one expect the Rand to be directly linked to Gold. Hence in the long run, as Gold price increases the South African Rand weakens resulting in a positive relationship and vice versa. This positive relationship is well pronounced especially when price momentum builds and a price trend is strong in gold. Though a strongest relationship has been observed in the Pound, the relationship shifted between two exchange rate type of regimes (regimes of low volatility and those of high volatility). In essence, Gold has only been a currency hedge to a degree that seems highly dependent on somewhat unpredictable political attitudes and events.

The study contributed to the general knowledge and general academic debate on the subject "Gold as a hedge" while simultaneously generating knowledge on the hedging ability of Gold on the South African Rand, a field of academic debate that is in a somehow developmental state.

The study a linear model which has its limitations and shortcomings as discussed in section 4 . The model estimated depicted high amount of volatility that shifted over time and could not be fully explained by an ordinary linear model. We therefore recommend that further research on the subject should employ much more sophisticated methodologies and models such us the non-linear model used by Kuan-Min and Yuan-Ming (2010).

\section{REFERENCES}

Ashley, R.A., and Patterson, D.M., 1989. Linear versus nonlinear Macroeconomics., International Economic Review, 30 (2), 685-704.

Financial Forecast Centre, Board of Governors of the Federal Reserve System, USA. Available at : http : //www.x - rates.com/d/GBP/USD/data120.html (Accessed on 22.08.2011).

Bollerslev, T. 1986. Generalised Autoregressive Conditional Heteroskedasticity. Journal of Econometrics., 31, 307-327.

Capie, F., Mills, T.C., and Wood, G., 2005. Gold as a Hedge against the Dollar. Journal of International Financial Markets, Institutions and Money., 15 (4), 343-352??

Craig, G.T., 2006. What is driving the Gold Price. Masters thesis, Rhodes University South Africa, Rhodes.

Dickey, D.A., and Fuller, W.A., 1979. Distribution of the Estimators for Autoregressive Time Series with a Unit Root. Journal of the American Association (Online), 74 (366), 427431.

Enders, W., 2010. Applied Econometric Time Series, 3rd Edition. Wiley New-York.

Engle, R.F., (1982). Autoregressive Conditional Heteroscedasticity with Estimates of Variance, United Kingdom Ination. Econometrica. 50, 987-008.

Webography Gold market, Finfacts Multimedia Limited. http://www.finfacts.ie/Private/curency/Goldmarketprice.htm. (accessed on 22.08.2011)

Glosten, L., Jaganathan, R., and Runkle, D., 1993. Relationship between the Expected Value and Volatility of the Nominal Excess Returns on Stocks. Journal of Finance, 48(5), 17791802.

Jastram, R. W., 2009. The Golden Constant: The English and American Experience 1560-2007 by Roy W Jastram with updated material by Jill Leyland. Edward Elgar Publishing Ltd (www.e-elgar.com), 368 pages, ISBN: 9781847202611.

Lawrence, C., (2003). Why is gold different from other assets, An empirical investigation?. Report, March 2003, World Gold Council, London, United Kingdom.

Ozturk, F. and Acikalin, S., 2008. Is Gold a Hedge Against the Turkish Lira. South East European Journal of Economics and Business. 3(1) 35-40. 35-40.

Nelson, D.B., 1991. Conditional Heteroskedasticity in Asset Returns: A New Approach. Econometrica., 59 (2) 347-370.

Kuan-Min, W., and Yuan-Ming, L., 2010 . Could Gold Serve as an Exchange Rate Hedge in Japan? Inzinerine-EkonomikaEngineering Economics, ISSN 1392-2785, 21 (2), 160-170.

Worthington, A.C. and Pahlavani, M., 2006. Cointegration evidence with allowance for endogenous structural break. Working papers series, \#05/06, University of Wollongong, School of Accounting and Finance.

Webography World Gold Council., ???? http : //www.Gold.org/investment/statistics/prices/. (accessed on 21.02.2011) 